\title{
Visual Perturbation to Enhance Return to Sport Rehabilitation after Anterior Cruciate Ligament Injury: A Clinical Commentary
}

\author{
Timothy R Wohl ${ }^{1}$, Cody R Criss ${ }^{2}$, Dustin R Grooms ${ }^{3}$ a \\ ${ }^{1}$ Honors Tutorial College, Ohio University, Athens, OH, USA; Division of Physical Therapy, School of Health and Rehabilitation Sciences, Ohio State \\ University, Columbus, OH, USA, 2 Ohio Musculoskeletal \& Neurological Institute, Ohio University, Grover Center, Athens, OH, USA; Translational \\ Biomedical Sciences, Heritage College of Osteopathic Medicine, Ohio University, Athens, $\mathrm{OH}$, USA, ${ }^{3}$ Ohio Musculoskeletal \& Neurological Institute, \\ Ohio University, Grover Center, Athens, OH, USA; Division of Athletic Training, School of Applied Health Sciences and Wellness, College of Health \\ Sciences and Professions, Ohio University, Grover Center, Athens, OH, USA; Division of Physical Therapy, School of Rehabilitation and Communication \\ Sciences, College of Health Sciences and Professions, Ohio University, Grover Center, Athens, OH, USA \\ Keywords: anterior cruciate ligament, acl, rehabilitation, stroboscopic glasses \\ https://doi.org/10.26603/001c.21251
}

International Journal of Sports Physical Therapy

Vol. 16, Issue 2, 2021

\begin{abstract}
Anterior cruciate ligament (ACL) tears are common traumatic knee injuries causing joint instability, quadriceps muscle weakness and impaired motor coordination. The neuromuscular consequences of injury are not limited to the joint and surrounding musculature, but may modulate central nervous system reorganization. Neuroimaging data suggest patients with ACL injuries may require greater levels of visual-motor and neurocognitive processing activity to sustain lower limb control relative to healthy matched counterparts. Therapy currently fails to adequately address these nuanced consequences of ACL injury, which likely contributes to impaired neuromuscular control when visually or cognitively challenged and high rates of re-injury. This gap in rehabilitation may be filled by visual perturbation training, which may reweight sensory neural processing toward proprioception and reduce the dependency on vision to perform lower extremity motor tasks and/or increase visuomotor processing efficiency. This clinical commentary details a novel approach to supplement the current standard of care for ACL injury by incorporating stroboscopic glasses with key motor learning principles customized to target visual and cognitive dependence for motor control after ACL injury.
\end{abstract}

\section{Level of Evidence}

5

\section{INTRODUCTION}

Anterior cruciate ligament (ACL) tears are common orthopedic injuries, ${ }^{1}$ involving an extensive plan of care and physical therapy following surgical reconstruction. ${ }^{2}$ Despite receiving comprehensive approaches to restore knee function, quadriceps strength, ${ }^{3,4}$ and joint stability, ${ }^{5-7}$ re-injury rates remain high, especially among young female athletes. ${ }^{4,8-17}$ This increased risk of re-injury may stem from nuanced neuromuscular consequences of ACL injury that therapy may not adequately address.

While ACL tears are peripheral joint injuries, the combination of effusion, pain, mechanical instability and deafferentation secondary to loss of joint mechanoreceptors may modulate central nervous system (CNS) reorganiza- tion. ${ }^{18,19}$ The CNS reorganization manifests as proprioceptive deficits and impaired motor coordination secondary to increased attentional, cognitive $20-23$ and visual relative to proprioceptive processing demands for motor control. ${ }^{20-35}$ A potential avenue to augment ACL rehabilitation is to facilitate sensory reweighting (nervous system adjustment of relative sensory input/processing for motor control) by shifting the post-injury reliance on vision for motor control to remaining proprioceptive inputs (e.g., the joint capsule, other ligaments, muscle spindles). Specifically, the use of visual perturbation training, which aims to reduce visual input availability during standard rehabilitative exercises, may reduce the dependency on vision and reweight neural processing toward proprioception and/or increase visuomotor processing efficiency. ${ }^{36}$ Additionally, the application of

\footnotetext{
a Corresponding author:

Dustin R. Grooms,

Ohio University,

Athens, Ohio, 45701,

groomsd@ohio.edu

T: 740.593.2552
} 
key motor learning principles may support visual perturbation training, such as 1) an external visual focus of attention or cueing to help ensure visuospatial demands during training and 2) implicit learning to reduce the cognitive requirements for motor control and promote movement automaticity. ${ }^{37-40}$ The following commentary details an example of a sensory reweighting protocol that combines the use of stroboscopic glasses and key motor learning principles.

\section{BEHAVIORAL SUPPORT FOR INCREASED VISUAL RELIANCE \& NEUROCOGNITIVE MOTOR PLANNING FOLLOWING ACL INJURY}

\section{INCREASED VISUAL RELIANCE}

A series of investigations in ACL deficient (ACL-D) and reconstructed (ACL-R) patients provide support for increased visual reliance for motor control. ${ }^{26-35}$ During postural control tasks, patients with ACL injuries and uninjured controls performed similarly when vision was unobstructed. 31,32 However, when vision was perturbed, patients with ACL injuries performed significantly worse (e.g., increased postural sway, failure in task completion). ${ }^{28,30,33-35}$ While a recent meta-analysis indicated patients with ACL-R are not as dependent on vision for postural control as patients with ACL-D, ${ }^{41}$ the mixed finding may be secondary to not challenging knee control during single-leg stance (by allowing a straight leg position), static postural control not being sufficiently challenging in those with reconstruction or complete vision obstruction not perturbating visuospatial processing sufficiently to elicit a deficit. This is exemplified by patients with ACL-R being more affected by visual perturbation (i.e., stroboscopic glasses) during drop landing and the transition from double to single leg stance with eyes closed and when challenged with visuocognitive tasks relative to matched controls. ${ }^{27,34,42}$

An increased weighting towards visual input and processing for postural and lower extremity motor control following ACL injury may emerge from a sensory reweighting phenomenon that is driven, in part, by insult to the underlying joint tissue and ligament mechanoreceptors. ${ }^{25}$ These mechanoreceptors, including Ruffini and Pacinian corpuscles, provide information about joint position, motion and acceleration, and their loss compromises proprioception and functional stability. ${ }^{43-46}$ Consequently, the CNS may employ functional strategies, such as sensory reweighting to more reliable stimuli (e.g., vision, vestibular), or increase cognitive and attentional processes to maintain adequate motor control. ${ }^{36,47-51}$ The Bayesian optimal integration model details how weighting sensory stimuli by reliability reduces the uncertainty of perception, thereby optimizing performance. ${ }^{52-54}$ Further, physical therapy following ACL injury may also increase visual attention to the knee, as clinicians primarily utilize visually-dominated exercises and provide feedback with an internal focus of attention (i.e., emphasizing movement kinematics or muscle activation, rather than movement actions) to the injured joint. ${ }^{37,55-59}$ However, weighting vision to guide lower limb movement may be maladaptive for athletes returning to a competitive sport environment, where the high demand to integrate dynamic visual information may limit the CNS's capacity to allocate neural resources to guide movement. Therefore, patients with ACL injuries may benefit from therapeutic interventions that encourage sensory reweighting from vision towards proprioception for motor control.

\section{INCREASED NEUROCOGNITIVE MOTOR PLANNING}

Excessive knee valgus has been identified as a major risk factor for primary and secondary ACL injury, with high sensitivity (78\%) and specificity (73\%). ${ }^{60}$ Herman and Barth identified a significant relationship between baseline neurocognition and knee valgus motion, where those with lower visual-memory and neurocognitive ability demonstrate increased knee valgus motion during a drop-landing task involving an unanticipated rebound immediately after landing. ${ }^{61}$ These studies suggest an athlete's baseline neurocognitive function may contribute to his or her risk of injury. ${ }^{60,61}$ A common therapeutic modality used to target neurocognitive function is dual-tasking, which involves the completion of two or more tasks simultaneously (e.g., balancing on one leg while counting down from 1,000 by 7). ${ }^{62}$ For example, patients with ACL injuries exhibit higher dual task-related costs during postural stability, gait and balance tasks. 23,63-66 Taken together, following ACL injury, patients may experience a reduced capability to simultaneously engage in cognitive processing and motor performance. Neural mechanisms for this deficit may be secondary to the disruption of typical ACL afferent information utilized by the primary motor cortex, which may result in increased frontal activity (e.g., presupplementary motor area, supplementary motor area) to compensate. ${ }^{21,67,68}$ Thus, the cognitive demands of sport may exceed the patient's capability to optimally attend to external visual stimuli (e.g., opponents, balls) and maintain low injury-risk biomechanics.

\section{NEUROIMAGING INVESTIGATIONS FOLLOWING ACL INJURY}

\section{ACL INJURY ASSOCIATED VISUOMOTOR \& VISUOSPATIAL BRAIN ACTIVATION}

Cross-sectional studies using functional magnetic resonance imaging (fMRI) have assessed neural activation differences for knee motor control in patients with ACL-D and ACL-R compared to uninjured, matched controls. ${ }^{20,21,69,70}$ In patients with ACL-D two years post-injury, fMRI identified increased activation in the posterior inferior temporal gyrus during a unilateral knee flexion/extension task. ${ }^{69}$ The posterior inferior temporal gyrus has been implicated in the recognition of biological movements, such as gait-like motion, rather than random motion. ${ }^{71}$ For patients with ACL$\mathrm{R} \sim 3$ years post-surgery, fMRI further identified increased neural activity within the lingual gyrus for both knee and combined hip-knee coordinated movements. ${ }^{70,72}$ The lingual gyrus is involved in the cross-modal integration of congruent visual and tactile stimuli in a spatially-specific manner. ${ }^{73,74}$ Increased neural activity requirements for the posterior inferior temporal gyrus and lingual gyrus corroborate the behavioral investigations, indicating an increased reliance or shift in visual information processing during 
motor control following ACL injury.

\section{ACL INJURY ASSOCIATED NEUROCOGNITIVE MOTOR PLANNING BRAIN ACTIVATION}

Other regions with increased neural activity include the presupplementary motor area in patients with ACL-D two years after injury as well as the frontal gyri, inferior frontal pole, paracingulate gyrus and anterior cingulate gyrus for patients with ACL-R five years post-surgery. ${ }^{22,69}$ While both injured populations performed identical tasks, differences in neural activation patterns are likely attributed to demographic (high vs. low functioning patients, activity level), surgical, time from injury, and rehabilitation protocol differences. Increased activation of the presupplementary motor area in patients with ACL-D may reflect increased cortical activity for planning simple movements. ${ }^{69}$ Increased activation across the frontal lobe in regions responsible for motor control further supports the hypothesis that patients with ACL injuries utilize increased cognitive resources for motor control by engaging in less efficient neural activation strategies. ${ }^{22}$ Neural efficiency refers to the reduced neural activity requirements of experts to perform a learned skill or task relative to novices, suggesting relative magnitude of neural activity scales with expertise and the ability to handle more complex coordination or environmental perturbations. ${ }^{75-78}$

The lack of neural efficiency and associated frontal region activity is corroborated with electroencephalography (EEG), indicating increased frontal theta power during force control and joint position tasks in patients with ACL-R one year post-surgery compared to uninjured controls. ${ }^{20,21}$ Frontal Theta power is an indicator of focused attention and task complexity, ${ }^{20}$ which may indicate that simple knee force control and joint position tasks are more complex and require greater attention for patients with ACL-R. Additionally, EEG has revealed that patients with ACL-D require more cognition/attention resources relative to healthy controls during walking, running and landing tasks as evidenced by significant increases in delta, theta, alpha, and beta band power, as well as asymmetry of the beta band power across the frontal and parietal lobes during jogging and landing. ${ }^{79}$ Increased activation across the frontal lobe, presupplementary motor area, increased frontal theta power during joint position sense and force matching tasks and increased cognition/attention during walking, jogging and landing support the behavioral data indicating increased neurocognitive motor planning neural activity following ACL injury. Taken together, patients with ACL injuries may experience a loss of neural efficiency to engage in motor control, thereby contributing to both 1) impaired motor performance during dual-tasking or unanticipated movements and 2) an increased risk of secondary injury when attempting to rapidly increase motor complexity and environmental stimuli during early return to sport. $^{23,63-66,80-82}$

\section{SENSORY REWEIGHTING THERAPY}

\section{VISUAL PERTURBATION TRAINING}

Functional navigation and interaction with the environ- ment rely heavily upon continual integration of visual information. ${ }^{71,83,84}$ Visual information processing is further recruited for motor control following ACL injury, potentially due to sensory reweighting from the deafferentation of joint mechanoreceptors and/or the use of visually-dominated exercises and internal feedback to the injured joint during physical therapy. ${ }^{36,37,55-59}$ While patients may be able to compensate with increased visual processing for simple exercises, an inundation of dynamic visual information on the sporting field may overwhelm neural processing resources and the visually biased movement compensation strategy may become a re-injury risk liability. ACL rehabilitation efforts may consider incorporating complex sensory challenges, like visual perturbation, in order to simulate the dynamic sport environment that athletes will face once they leave the clinic. ${ }^{20,21,29,85-87}$

Stroboscopic glasses (SG) provide a novel approach to train visuomotor function by perturbating and reducing visual feedback. ${ }^{36}$ Typically, visual perturbation training has been limited to eyes open and eyes closed conditions with no progression between, but SG provides the ability to incrementally perturb visual information by increasing the duration of the opaque state (range: 25 to $900 \mathrm{msec}$ ) relative to the constant duration of the transparent state (100 msec). ${ }^{88}$ Originally designed to be a mobile sports training tool, SG has allowed researchers to investigate the effects of perturbed vision in context-specific environments. ${ }^{89}$ Early research with SG explored behavioral performance on motion coherence, divided attention, multiple-object tracking, ${ }^{90}$ short-term visual memory, ${ }^{91}$ and anticipation, ${ }^{92}$ as well as performance on sports-specific tasks from singleleg squatting, ${ }^{93}$ ice hockey, ${ }^{94}$ tennis, ${ }^{95}$ and badminton. ${ }^{96}$ These authors concluded visual perturbation training improves sport-specific behavioral performance and aspects of neurocognition including visual memory, anticipatory timing of moving visual stimuli, and central visual field motion sensitivity and transient attention ability.

SG simulates the dynamic visuomotor and cognitive/attentional demands of athletic activity while remaining in a controlled clinical environment. ${ }^{92,94,97,98}$ As patients with ACL injuries exhibit degraded motor control during dropjump landing, cutting, and postural control under impaired visual conditions relative to normal vision, ${ }^{27,28,30,33-35,99,100}$ SG may facilitate increased proprioceptive integration in response to perturbed visuospatial information. ${ }^{36,89}$ ACL rehabilitation efforts that incorporate SG may be able to alter sensory weighting by decreasing the amount of visual information available to the athlete, thereby requiring the athlete to upregulate their use of remaining proprioceptive or vestibular inputs to guide movement. Utilizing SG in ACL rehabilitation may also enhance visuomotor processing efficiency in a compensatory manner to handle the increased reliance on vision to maintain low injury-risk biomechanics. ${ }^{48}$

\section{MOTOR LEARNING PRINCIPLES}

A key limitation of ACL rehabilitation is the inability to facilitate the acquisition of injury-resistant motor patterns that persist beyond the clinic. ${ }^{101}$ This limitation likely contributes to high rates of secondary injury and long-term 
pathologic sequalae, such as aberrant joint loading and early-onset osteoarthritis. ${ }^{102}$ The incorporation of motor learning principles may facilitate the acquisition of lasting, injury-resistant movement patterns that persist beyond the clinic and into the field, ${ }^{103}$ since these principles can facilitate neuroplasticity in cortical regions dedicated to movement. ${ }^{104,105}$ Specifically, the use of an external focus of attention and implicit learning may serve an adjunctive role to sensory reweighting therapy. An external visual focus of attention can ensure visuospatial demands during training and implicit learning can reduce the cognitive demands for motor control to potentially enhance training. ${ }^{37-40}$

\section{MODIFIED EXTERNAL FOCUS OF ATTENTION FOR VISUOSPATIAL ATTENTION}

While the classic definition of external focus (EF) feedback is purely an attentional manipulation, this clinical commentary modified the traditional EF framework to push attentional focus toward the external visuospatial environment. ACL therapy that employs a visual EF can simulate real-world training scenarios that better prepare athletes for return to activity when visual attention is focused on the environment and not the body. Training with EF prioritizes the movement goal or the movement's effect on the environment, rather than an internal focus (IF) on the movement or body segment itself. ${ }^{106}$ For example, a therapist who directs patients to balance a light-weight bar horizontally with their outstretched arm while performing a singleleg balance task employs visual EF. ${ }^{37,107}$ In contrast, a therapist who directs patients to actively attend to their ankle, knee and hip alignment while balancing employs IF, which is the predominant strategy in ACL therapy. An IF approach to therapy may hinder the translational benefits of rehabilitation, as humans typically navigate the world with a visual EF on the environment (e.g., running to a ball) - not on their moving joints or mechanics. ${ }^{108}$

The Constrained Action Hypothesis posits conscious (cortical) awareness of movement constrains the automatic, subcortical processes that would otherwise facilitate movement. ${ }^{109}$ By training with $\mathrm{EF}$, one may relieve the attentional demands on the cortex by shifting motor control to subcortical regions and enhance motor learning and performance relative to training with IF. ${ }^{102,110-113}$ Behaviorally, training with EF improves agility performance, ${ }^{57}$ increases jump height, ${ }^{114}$ and promotes safer landing patterns during a single-leg hop for distance task in patients with ACL-R compared to performance with IF. ${ }^{115}$ Additionally, engaging in EF increases time to failure, reduces ratings of perceived exertion, ${ }^{116,117}$ and increases movement efficiency potentially by reducing unnecessary muscle contributions by modulating the inhibitory mechanisms within the primary motor cortex. 117,118

\section{IMPLICIT LEARNING}

Developmentally, humans learn to move through observation and implicit trial-and-error (e.g., learning to ride a bike, walk, throw). ${ }^{119}$ Implicit feedback facilitates motor learning without explicit, declarative instructions or cuing, ${ }^{37}$ thereby increasing neural efficiency by reducing the attentional demands to engage in complex movement. While explicit cuing engages cognitive processes (frontoparietal regions), implicit cuing facilitates more direct sensorimotor activity. ${ }^{120}$ Further, training with implicit cuing has recently been associated with motor cortex reorganization, potentially supporting more efficient premotor or cortical interneuron processes. ${ }^{121}$ While few studies have examined the behavioral impacts of implicit cues for sports medicine, Popovic et al. demonstrated improved landing biomechanics with implicit feedback relative to explicit/no feedback. ${ }^{40}$ Thus, instructional language informed by implicit learning may augment visual perturbation training by modulating sensorimotor neural activity and potentially increasing neural efficiency by reducing the cognitive load of learning injury-resistant movement strategies. The newly freed cortical resources may enable athletes to more readily attend to visual distractors during high-level sport (e.g., the ball, opponents) while maintaining neuromuscular control. 37,122

For example, consider the scenario where a therapist trains an athlete with an ACL injury to land correctly after a drop vertical jump. A therapist may opt to follow an explicit learning model and inform the athlete of all the biomechanical variables he or she is evaluating (e.g., trunk flexion, knee flexion, knee valgus, foot rotation, etc.). This type of learning requires the athlete to attend to multiple aspects of his or her landing mechanics, thereby occupying a substantial amount of his or her cognitive resources. However, a therapist who opts-in to implicit learning may instead provide metaphorical instructional language (e.g., "land like a feather") and simple "yes/no" or "good/bad" feedback to train the athlete to land. This trial-and-error method may augment visual perturbation training by alleviating the burden of attending to biomechanical variables, thereby freeing the athlete's cognitive resources to attend to external visual stimuli without compromising their neuromuscular control.

\section{CLINICAL APPLICATION}

Future studies are needed to explore the therapeutic efficacy of combining SG and motor learning principles (i.e., $\mathrm{EF}$, implicit learning) with traditional therapeutic exercises during ACL rehabilitation. A barrier to such studies is a lack of clearly defined and easily replicable exercises that combine these novel modalities. This clinical commentary details ways therapists and researchers can supplement the current standard of care by adding SG and motor learning principles to agility, balance and plyometric exercises in novel ways. Provided are example exercises with specific instructional language and visual targets (Table 1). Further clinical examples of EF and implicit learning can be found in the work of Gokeler et al. ${ }^{37}$ An error scoring system with detailed criteria to assess behavioral performance while wearing SG is provided as well (Table 2).

\section{AGILITY DRILLS}

(1) The T-test requires the athlete to run $10 \mathrm{~m}$ to tap a cone, cut to the right or left for $5 \mathrm{~m}$ to tap another cone, cut to the opposite direction for $10 \mathrm{~m}$ to tap the third cone, re- 
Table 1: Instrumentation and Instruction to Facilitate Perception-Action that Employs Visual External Focus and Implicit Learning Principles.

\begin{tabular}{|l|l|l|}
\hline Exercise & Visual Cues & Implicit Cues \\
\hline T-test & Tap the cones & "Run as fast as a cheetah" \\
\hline Agility Ladder Drills & The confines of the ladder & "The floor is as hot as lava" \\
\hline Single-leg Deadlifts & Place an object by the cone(s) & "Flow like water" \\
\hline Single-leg Stance (on foam) & Hold the bar horizontally & "Be steady as a rock" \\
\hline Vertical Jumps & Hit the overhead target & "Explode like a volcano" \\
\hline Squat Jumps & Land facing the cones & "Jump like a kangaroo" \\
\hline
\end{tabular}

Table 2: Error Scoring System Used to Assess Behavioral Performance.

\begin{tabular}{|c|c|}
\hline Exercise & Error Count \\
\hline T-test & $\begin{array}{l}\text { 1. Miss a cone } \\
\text { 2. Cut to the wrong direction }\end{array}$ \\
\hline Agility Ladder Drills & $\begin{array}{l}\text { 1. Hit the ladder } \\
\text { 2. Incorrect foot placement }\end{array}$ \\
\hline Single-leg Deadlifts & $\begin{array}{l}\text { 1. Opposite foot touches ground } \\
\text { 2. Either hand touches ground } \\
\text { 3. Object placed in wrong location }\end{array}$ \\
\hline Single-leg Stance (on foam) & $\begin{array}{l}\text { 1. Opposite foot touches ground } \\
\text { 2. Either hand touches ground }\end{array}$ \\
\hline Vertical Jumps & $\begin{array}{l}\text { 1. Miss the target } \\
\text { 2. Land on wrong foot }\end{array}$ \\
\hline Squat Jumps & 1. Land facing wrong orientation \\
\hline
\end{tabular}

turn to the center by cutting $5 \mathrm{~m}$ to tap the first cone and then run $10 \mathrm{~m}$ back to the start position - thereby running in $\mathrm{a}$ " $\mathrm{T}$ " formation (Figure 1A). A modification that increases the difficulty of this task and simulates the cognitive demands of sport is to have the clinician call out "Left" or "Right" to indicate which direction the athlete should cut prior to reaching the first cone, thereby creating an unanticipated cutting task which has been previously associated with increased injury-risk biomechanics compared to anticipated trials. ${ }^{123}$ (2) Agility ladder drills require athletes to match specified foot-placement patterns within the context of an agility ladder (Figure 1B).

\section{BALANCE}

(1) Single-leg deadlifts may be modified by requiring athletes to gently place a small object on the ground next to a cone target (Figure 1C). To increase the difficulty, multiple cones can be placed at different angles within the athlete's field-of-view, set at distances equal to his or her max volitional reaching distance while standing on one leg. For example, if the clinician chooses to use three targets, then he or she may call out "Left," "Center," or "Right" to vary the task order and difficulty. (2) Single-leg stance on a foam surface may be modified by having the participant hold a light-weight bar with an outstretched arm and focus on keeping it steadily horizontal (Figure 1D).

\section{PLYOMETRICS}

(1) The VERTEC is a therapeutic tool that assesses maximum vertical jump height by requiring athletes to jump and hit an overhead target (Figure 1E). While using the VERTEC to have athletes hit a mark equal to $80 \%$ of their maximal jump height, clinicians may call out "Left" or "Right" during the initial flight phase of the jump to signal to the athlete to unilaterally land on his or her left or right leg. ${ }^{124,125}$ The use of spontaneous cuing creates an unanticipated landing task, which has been previously associated with increased injury-risk biomechanics compared to anticipated land- 


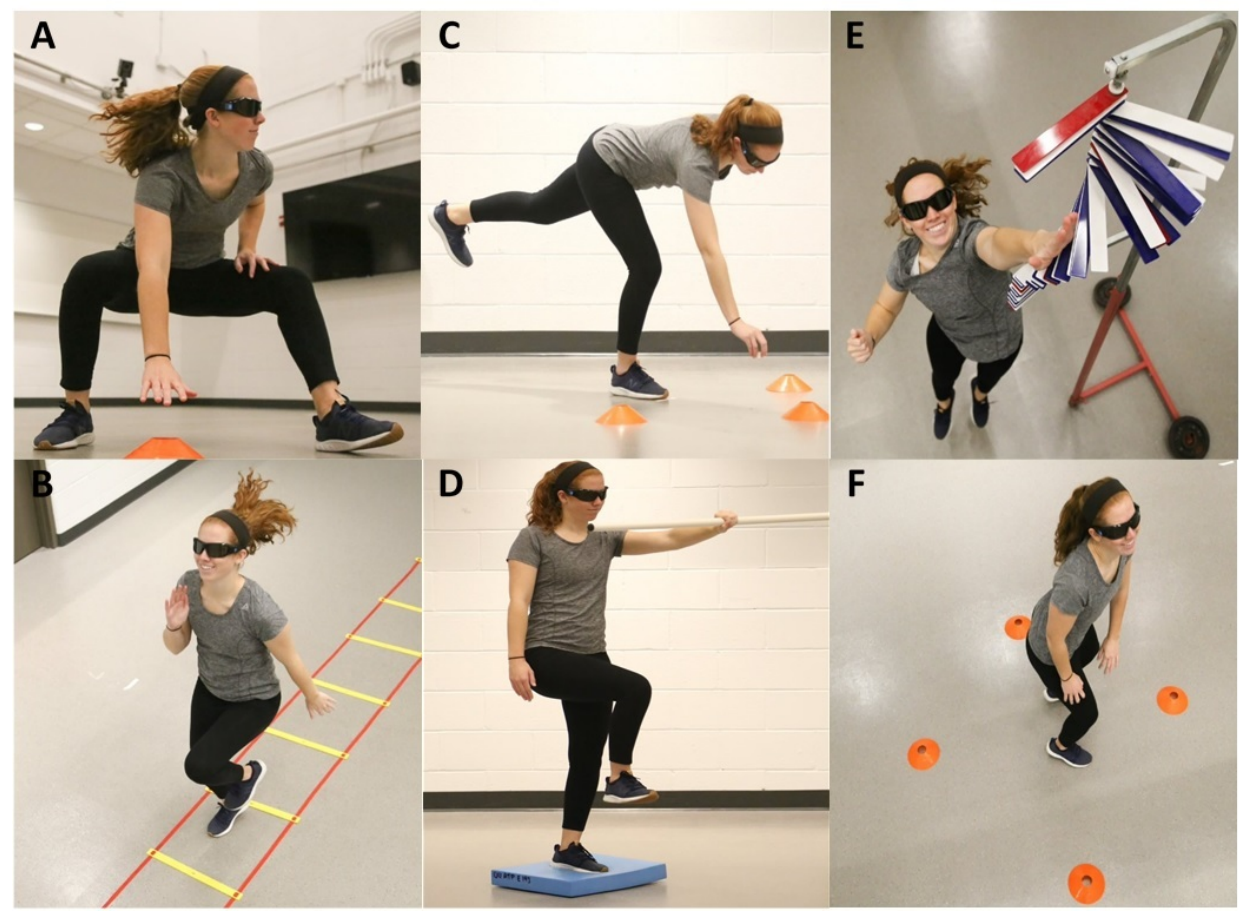

Figure 1: Exercise examples with clinical applications: (A) T-test, (B) Agility ladder drills, (C) Single-leg deadlifts, (D) Single-leg stance (on foam), (E) Vertical jumps, and (F) Squat jumps.

ing. ${ }^{126}$ (2) Jump squats may be modified by placing four cones around the participant at $0,90,180$ and 270 degree positions (Figure 1F). After numbering each cone one through four, the clinician may then rapidly call out cues to the athlete to specify which cone they should face after each jump squat. To increase the difficulty of this cognitive challenge, the clinician can introduce more cones or increase the rapidity of cuing.

\section{SG LEVEL}

Clinicians should first verify their athlete can perform all exercises successfully before incorporating SG. Then clinicians may expose their athlete to SG by beginning at the easiest difficulty level (highest frequency of fluctuation between transparent and opaque states). As their athlete improves performance behaviorally, clinicians may increase SG difficulty to increase the visual-cognitive demand.

In addition to the provided Error Scoring System (Table 2), clinicians may use the NASA Task Load Index questionnaire or Borg's Rating of Perceived Exertion scale to optimize the SG difficulty level during training. ${ }^{127-129}$ These tools allow clinicians to assess an athlete's perceived level of difficulty performing exercises with SG. For example, if clinicians want to simulate "hard/difficult" sports scenarios with SG, but their athlete rates his or her experience as "moderate," clinicians may increase the visual perturbation by raising the SG difficulty level.

Alternatively, clinicians may opt to only incorporate SG into exercises that are below their athlete's current physical capability initially. For example, if an athlete only recently performed a single-leg hop successfully, their clinician may choose to perturbate a single-leg balance exercise by adding SG. After successful completion of the single-leg balance exercise with SG, the clinician may then choose to advance the athlete's training by incorporating SG into the harder single-leg hop task. This style of initially incorporating perturbations into exercises that are below a patient's current physical capability is common in rehabilitation.

\section{CONCLUSION}

A novel approach to ACL rehabilitation that incorporates sensory reweighting therapy may shift neural processing toward proprioception and reduce the dependency on vision for motor control and/or increase visuomotor efficiency. ACL rehabilitation efforts that incorporate visual-perturbation training supplemented by motor learning principles (visual EF and implicit learning) may fill this gap. Future studies are needed to evaluate the therapeutic efficacy of sensory reweighting therapy in ACL rehabilitation.

\section{CONFLICTS OF INTEREST}

The authors report no conflicts of interest.

Submitted: April 26, 2020 CDT, Accepted: October 10, 2020 CDT 

(CCBY-NC-SA-4.0). View this license's legal deed at https://creativecommons.org/licenses/by-nc-sa/4.0 and legal code at https://creativecommons.org/licenses/by-nc-sa/4.0/legalcode for more information. 


\section{REFERENCES}

1. Sanders TL, Maradit Kremers H, Bryan AJ, et al. Incidence of anterior cruciate ligament tears and reconstruction: A 21-year population-based study. Am J Sports Med. 2016;44(6):1502-1507. doi:10.1177/0 $\underline{363546516629944}$

2. Marx RG, Jones EC, Angel M, Wickiewicz TL, Warren RF. Beliefs and attitudes of members of the American Academy of Orthopaedic Surgeons regarding the treatment of anterior cruciate ligament injury. Arthrosc J Arthrosc Relat Surg. 2003;19(7):762-770.

3. Cavanaugh JT, Powers M. ACL Rehabilitation progression: Where are we now? Curr Rev Musculoskelet Med. 2017;10(3):289-296. doi:10.1007/s 12178-017-9426-3

4. Wright RW, Haas AK, Anderson J, et al. Anterior cruciate ligament reconstruction rehabilitation: MOON guidelines. Sports Health. 2015;7(3):239-243. doi:10.1177/1941738113517855

5. Melick N van, Cingel REH van, Brooijmans F, et al. Evidence-based clinical practice update: practice guidelines for anterior cruciate ligament rehabilitation based on a systematic review and multidisciplinary consensus. Br J Sports Med. 2016;50(24):1506-1515. doi:10.1136/bjsports-2015-09 $\underline{5898}$

6. Greenberg EM, Greenberg ET, Albaugh J, Storey E, Ganley TJ. Rehabilitation practice patterns following anterior cruciate ligament reconstruction: A survey of physical therapists. J Orthop Sports Phys Ther. 2018;48(10):801-811. doi:10.2519/jospt.2018.8264

7. Simoneau GG, Wilk KE. The challenge of return to sports for patients post-ACL reconstruction. J Orthop Sports Phys Ther. 2012;42(4):300-301. doi:10.2519/jos pt.2012.0106

8. Hui C, Salmon LJ, Kok A, Maeno S, Linklater J, Pinczewski LA. Fifteen-year outcome of endoscopic anterior cruciate ligament reconstruction with patellar tendon autograft for "isolated" anterior cruciate ligament tear. Am J Sports Med. 2011;39(1):89-98. doi:10.1177/0363546510379975

9. Paterno MV, Schmitt LC, Ford KR, et al. Biomechanical measures during landing and postural stability predict second anterior cruciate ligament injury after anterior cruciate ligament reconstruction and return to sport. Am J Sports Med. 2010;38(10):1968-1978. doi:10.1177/03635465103760 $\underline{53}$
10. Paterno MV, Rauh MJ, Schmitt LC, Ford KR, Hewett TE. Incidence of contralateral and ipsilateral anterior cruciate ligament (ACL) injury after primary ACL reconstruction and return to sport. Clin J Sport Med Off J Can Acad Sport Med. 2012;22(2):116-121. do i:10.1097/JSM.0b013e318246ef9e

11. Salmon L, Russell V, Musgrove T, Pinczewski L, Refshauge K. Incidence and risk factors for graft rupture and contralateral rupture after anterior cruciate ligament reconstruction. Arthroscopy. 2005;21(8):948-957. doi:10.1016/j.arthro.2005.04.110

12. Shelbourne KD, Gray T, Haro M. Incidence of subsequent injury to either knee within 5 years after anterior cruciate ligament reconstruction with patellar tendon autograft. Am J Sports Med. 2009;37(2):246-251. doi:10.1177/0363546508325665

13. Gomez E, DeLee JC, Farney WC. Incidence of injury in texas girls' high school basketball. Am J Sports Med. 1996;24(5):684-687. doi:10.1177/0363546 59602400521

14. Lyman S, Koulouvaris P, Sherman S, Do H, Mandl LA, Marx RG. Epidemiology of anterior cruciate ligament reconstruction: trends, readmissions, and subsequent knee surgery. J Bone Joint Surg Am. 2009;91(10):2321-2328. doi:10.2106/JBJS.H.00539

15. Messina DF, Farney WC, DeLee JC. The incidence of injury in Texas high school basketball. A prospective study among male and female athletes. Am J Sports Med. 1999;27(3):294-299. doi:10.1177/036 $\underline{35465990270030401}$

16. Pinczewski LA, Lyman J, Salmon LJ, Russell VJ, Roe J, Linklater J. A 10-year comparison of anterior cruciate ligament reconstructions with hamstring tendon and patellar tendon autograft: a controlled, prospective trial. Am J Sports Med. 2007;35(4):564-574. doi:10.1177/0363546506296042

17. Rauh MJ, Macera CA, Ji M, Wiksten DL. Subsequent injury patterns in girls' high school sports. J Athl Train. 2007;42(4):486-494.

18. Ageberg E. Consequences of a ligament injury on neuromuscular function and relevance to rehabilitation - using the anterior cruciate ligamentinjured knee as model. J Electromyogr Kinesiol Off J Int Soc Electrophysiol Kinesiol. 2002;12(3):205-212. 
19. Ingersoll CD, Grindstaff TL, Pietrosimone BG, Hart JM. Neuromuscular consequences of anterior cruciate ligament injury. Clin Sports Med. 2008;27(3):383-404, vii. doi:10.1016/j.csm.2008.03.00 $\underline{4}$

20. Baumeister J, Reinecke K, Weiss M. Changed cortical activity after anterior cruciate ligament reconstruction in a joint position paradigm: an EEG study. Scand J Med Sci Sports. 2008;18(4):473-484. do i:10.1111/i.1600-0838.2007.00702.x

21. Baumeister J, Reinecke K, Schubert M, Weiss M. Altered electrocortical brain activity after ACL reconstruction during force control. J Orthop Res Off Publ Orthop Res Soc. 2011;29(9):1383-1389. doi:10.10 $\underline{02 / j o r .21380}$

22. Lepley AS, Grooms DR, Burland JP, Davi SM, Kinsella-Shaw JM, Lepley LK. Quadriceps muscle function following anterior cruciate ligament reconstruction: systemic differences in neural and morphological characteristics. Exp Brain Res. 2019;237(5):1267-1278. doi:10.1007/s00221-019-054 99-X

23. Negahban H, Ahmadi P, Salehi R, Mehravar M, Goharpey S. Attentional demands of postural control during single leg stance in patients with anterior cruciate ligament reconstruction. Neurosci Lett. 2013;556:118-123. doi:10.1016/i.neulet.2013.10.022

24. Kapreli E, Athanasopoulos S. The anterior cruciate ligament deficiency as a model of brain plasticity. Med Hypotheses. 2006;67(3):645-650. doi:10.1016/j.m ehy.2006.01.063

25. Ward S, Pearce AJ, Pietrosimone B, Bennell K, Clark R, Bryant AL. Neuromuscular deficits after peripheral joint injury: a neurophysiological hypothesis. Muscle Nerve. 2015;51(3):327-332. doi:1 $\underline{0.1002 / \text { mus. } 24463}$

26. Bjornaraa J, Di Fabio RP. Knee kinematics following acl reconstruction in females; the effect of vision on performance during a cutting task. Int J Sports Phys Ther. 2011;6(4):271-284.

27. Grooms DR, Chaudhari A, Page SI, Nichols-Larsen DS, Onate JA. Visual-motor control of drop landing after anterior cruciate ligament reconstruction. J Athl Train. 2018;53(5):486-496. doi:10.4085/1062-6050-17 $\underline{8-16}$

28. Dauty M, Collon S, Dubois C. Change in posture control after recent knee anterior cruciate ligament reconstruction? Clin Physiol Funct Imaging. 2010;30(3):187-191. doi:10.1111/j.1475-097X.2010.00 926.X
29. Fridén T, Roberts D, Movin T, Wredmark T. Function after anterior cruciate ligament injuries. Influence of visual control and proprioception. Acta Orthop Scand. 1998;69(6):590-594.

30. Wikstrom EA, Song K, Pietrosimone BG, Blackburn JT, Padua DA. Visual utilization during postural control in anterior cruciate ligamentdeficient and -reconstructed patients: Systematic reviews and meta-analyses. Arch Phys Med Rehabil. 2017;98(10):2052-2065. doi:10.1016/j.apmr.2017.04.0 $\underline{10}$

31. Hoffman M, Schrader J, Koceja D. An Investigation of postural control in postoperative anterior cruciate ligament reconstruction patients. J Athl Train. 1999;34(2):130-136.

32. Mattacola CG, Perrin DH, Gansneder BM, Gieck $\mathrm{JH}$, Saliba EN, McCue FC. Strength, functional outcome, and postural stability after anterior cruciate ligament reconstruction. J Athl Train. 2002;37(3):262-268.

33. O’Connell M, George K, Stock D. Postural sway and balance testing: a comparison of normal and anterior cruciate ligament deficient knees. Gait Posture. 1998;8(2):136-142. doi:10.1016/s0966-6362(9 8)00023-X

34. Dingenen B, Janssens L, Claes S, Bellemans J, Staes FF. Postural stability deficits during the transition from double-leg stance to single-leg stance in anterior cruciate ligament reconstructed subjects. Hum Mov Sci. 2015;41:46-58. doi:10.1016/j.humov.20 $\underline{15.02 .001}$

35. Okuda K, Abe N, Katayama Y, Senda M, Kuroda T, Inoue $\mathrm{H}$. Effect of vision on postural sway in anterior cruciate ligament injured knees. J Orthop Sci Off J Jpn Orthop Assoc. 2005;10(3):277-283. doi:10.1007/s0077 6-005-0893-9

36. Grooms D, Appelbaum G, Onate J. Neuroplasticity following anterior cruciate ligament injury: a framework for visual-motor training approaches in rehabilitation. J Orthop Sports Phys Ther. 2015;45(5):381-393. doi:10.2519/jospt.2015.5549

37. Gokeler A, Neuhaus D, Benjaminse A, Grooms DR, Baumeister J. Principles of motor learning to support neuroplasticity after ACL injury: Implications for optimizing performance and reducing risk of second ACL injury. Sports Med. 2019;49(6):853-865. doi:10.10 07/s40279-019-01058-0

38. Kantak SS, Mummidisetty CK, Stinear JW. Primary motor and premotor cortex in implicit sequence learning--evidence for competition between implicit and explicit human motor memory systems. Eur J Neurosci. 2012;36(5):2710-2715. doi:10.1111/j.1460-9 $\underline{568.2012 .08175 . x}$ 
39. Porter J, Makaruk H, Starzak M. The role of vision and movement automization on the focus of attention effect. J Mot Learn Dev. 2016;4:152-168. do i:10.1123/jmld.2015-0020

40. Popovic T, Caswell SV, Benjaminse A, Siragy T, Ambegaonkar J, Cortes N. Implicit video feedback produces positive changes in landing mechanics. $J$ Exp Orthop. 2018;5. doi:10.1186/s40634-018-0129-5

41. Bodkin SG, Slater LV, Norte GE, Goetschius J, Hart JM. ACL reconstructed individuals do not demonstrate deficits in postural control as measured by single-leg balance. Gait Posture. 2018;66:296-299. doi:10.1016/j.gaitpost.2018.06.120

42. Miko SC, Simon JE, Monfort SM, Yom JP, Ulloa S, Grooms DR. Postural stability during visual-based cognitive and motor dual-tasks after ACLR. J Sci Med Sport. July 2020. doi:10.1016/j.jsams.2020.07.008

43. Kennedy JC, Alexander IJ, Hayes KC. Nerve supply of the human knee and its functional importance. Am J Sports Med. 1982;10(6):329-335. doi:10.1177/036354 $\underline{658201000601}$

44. Schutte MJ, Dabezies EJ, Zimny ML, Happel LT. Neural anatomy of the human anterior cruciate ligament. J Bone Joint Surg Am. 1987;69(2):243-247.

45. Zimny ML, Schutte M, Dabezies E.

Mechanoreceptors in the human anterior cruciate ligament. Anat Rec. 1986;214(2):204-209. doi:10.100 2/ar.1092140216

46. Dhillon MS, Bali K, Prabhakar S. Proprioception in anterior cruciate ligament deficient knees and its relevance in anterior cruciate ligament reconstruction. Indian J Orthop. 2011;45(4):294-300. $\underline{\text { doi:10.4103/0019-5413.80320 }}$

47. Assländer L, Peterka RJ. Sensory reweighting dynamics in human postural control. J Neurophysiol. 2014;111(9):1852-1864. doi:10.1152/in.00669.2013

48. Kabbaligere R, Lee B-C, Layne CS. Balancing sensory inputs: Sensory reweighting of ankle proprioception and vision during a bipedal posture task. Gait Posture. 2017;52:244-250. doi:10.1016/j.gait post.2016.12.009

49. Sober SJ, Sabes PN. Multisensory integration during motor planning. J Neurosci Off J Soc Neurosci. 2003;23(18):6982-6992.

50. Bonfim TR, Jansen Paccola CA, Barela JA. Proprioceptive and behavior impairments in individuals with anterior cruciate ligament reconstructed knees. Arch Phys Med Rehabil. 2003;84(8):1217-1223. doi:10.1016/s0003-9993(03)00 $\underline{147-3}$
51. Fischer-Rasmussen T, Jensen PE. Proprioceptive sensitivity and performance in anterior cruciate ligament-deficient knee joints. Scand J Med Sci Sports. 2000;10(2):85-89. doi:10.1034/j.1600-0838.2000.0100 02085.X

52. Battaglia PW, Jacobs RA, Aslin RN. Bayesian integration of visual and auditory signals for spatial localization. JOSA A. 2003;20(7):1391-1397. doi:10.13 64/JOSAA.20.001391

53. Ernst MO, Banks MS. Humans integrate visual and haptic information in a statistically optimal fashion. Nature. 2002;415(6870):429. doi:10.1038/415429a

54. Knill DC, Pouget A. The Bayesian brain: the role of uncertainty in neural coding and computation. Trends Neurosci. 2004;27(12):712-719. doi:10.1016/j.ti ns.2004.10.007

55. Johnson L, Burridge JH, Demain SH. Internal and external focus of attention during gait re-education: an observational study of physical therapist practice in stroke rehabilitation. Phys Ther. 2013;93(7):957-966. doi:10.2522/pti.20120300

56. Halperin I, Chapman DW, Martin DT, Abbiss CR, Wulf G. Coaching cues in amateur boxing: an analysis of ringside feedback provided between rounds of competition. Psychol Sport Exerc. 2016;25:44-50.

57. Porter JM, Nolan RP, Ostrowski EJ, Wulf G. Directing attention externally enhances agility performance: a qualitative and quantitative analysis of the efficacy of using verbal instructions to focus attention. Front Psychol. 2010;1:216. doi:10.3389/fpsy g.2010.00216

58. Durham K, Van Vliet PM, Badger F, Sackley C. Use of information feedback and attentional focus of feedback in treating the person with a hemiplegic arm. Physiother Res Int J Res Clin Phys Ther. 2009;14(2):77-90. doi:10.1002/pri.431

59. Hunt C, Paez A, Folmar E. The impact of attentional focus on the treatment of musculoskeletal and movement disorders. Int J Sports Phys Ther. 2017;12(6):901-907.

60. Hewett TE, Myer GD, Ford KR, et al. Biomechanical measures of neuromuscular control and valgus loading of the knee predict anterior cruciate ligament injury risk in female athletes: a prospective study. Am J Sports Med. 2005;33(4):492-501. doi:10.1177/0363546504269591

61. Herman DC, Barth JT. Drop-jump landing varies with baseline neurocognition: Implications for anterior cruciate ligament injury risk and prevention. Am J Sports Med. 2016;44(9):2347-2353. doi:10.1177/0 $\underline{363546516657338}$ 
62. Burcal CJ, Needle AR, Custer L, Rosen AB. The effects of cognitive loading on motor behavior in injured individuals: a systematic review. Sports Med Auckl NZ. 2019;49(8):1233-1253. doi:10.1007/s4027 9-019-01116-7

63. Mohammadi-Rad S, Salavati M, EbrahimiTakamjani I, et al. Dual-tasking effects on dynamic postural stability in athletes with and without anterior cruciate ligament reconstruction. J Sport Rehabil. 2016;25(4):324-329. doi:10.1123/jsr.2015-00 $\underline{12}$

64. Nazary-Moghadam S, Salavati M, Esteki A, Akhbari B, Keyhani S, Zeinalzadeh A. Gait speed is more challenging than cognitive load on the strideto-stride variability in individuals with anterior cruciate ligament deficiency. Knee. 2019;26(1):88-96. doi:10.1016/j.knee.2018.11.009

65. Shi H, Huang H, Yu Y, et al. Effect of dual task on gait asymmetry in patients after anterior cruciate ligament reconstruction. Sci Rep. 2018;8. doi:10.1038/ s41598-018-30459-w

66. Akhbari B, Salavati M, Ahadi J, et al. Reliability of dynamic balance simultaneously with cognitive performance in patients with ACL deficiency and after ACL reconstructions and in healthy controls. Knee Surg Sports Traumatol Arthrosc Off J ESSKA. 2015;23(11):3178-3185. doi:10.1007/s00167-014-311 $\underline{6-0}$

67. Te M, Baptista AF, Chipchase LS, Schabrun SM. Primary motor cortex organization is altered in persistent patellofemoral pain. Pain Med. 2017;18(11):2224-2234. doi:10.1093/pm/pnx036

68. Shanahan CJ, Hodges PW, Wrigley TV, Bennell KL, Farrell MJ. Organisation of the motor cortex differs between people with and without knee osteoarthritis. Arthritis Res Ther. 2015;17:164. doi:10.1186/s13075-0 15-0676-4

69. Kapreli E, Athanasopoulos S, Gliatis J, et al. Anterior cruciate ligament deficiency causes brain plasticity: a functional MRI study. Am J Sports Med. 2009;37(12):2419-2426. doi:10.1177/03635465093432 01

70. Grooms DR, Page SJ, Nichols-Larsen DS, Chaudhari AMW, White SE, Onate JA. Neuroplasticity associated with anterior cruciate ligament reconstruction. J Orthop Sports Phys Ther. 2016;47(3):180-189. doi:10.2519/jospt.2017.7003

71. Peuskens H, Vanrie J, Verfaillie K, Orban GA. Specificity of regions processing biological motion. Eur J Neurosci. 2005;21(10):2864-2875. doi:10.1111/ j.1460-9568.2005.04106.X
72. Criss CR, Onate JA, Grooms DR. Neural activity for hip-knee control in those with anterior cruciate ligament reconstruction: A task-based functional connectivity analysis. Neurosci Lett. 2020;730:134985. doi:10.1016/j.neulet.2020.134985

73. Macaluso E, Frith CD, Driver J. Modulation of human visual cortex by crossmodal spatial attention. Science. 2000;289(5482):1206-1208.

74. Macaluso E, Driver J. Spatial attention and crossmodal interactions between vision and touch. Neuropsychologia. 2001;39(12):1304-1316.

75. Rypma B, Berger JS, Prabhakaran V, et al. Neural correlates of cognitive efficiency. NeuroImage. 2006;33(3):969-979. doi:10.1016/j.neuroimage.2006.0 $\underline{5.065}$

76. Costanzo ME, VanMeter JW, Janelle CM, et al. Neural efficiency in expert cognitive-motor performers during affective challenge. J Mot Behav. 2016;48(6):573-588. doi:10.1080/00222895.2016.1161 $\underline{591}$

77. Del Percio C, Rossini PM, Marzano N, et al. Is there a "neural efficiency" in athletes? a highresolution eeg study. Neuroimage.

2008;42(4):1544-1553. doi:10.1016/j.neuroimage.200 $\underline{8.05 .061}$

78. Del Percio C, Babiloni C, Marzano N, et al. "neural efficiency” of athletes' brain for upright standing: a high-resolution eeg study. Brain Res Bull. 2009;79(3-4):193-200. doi:10.1016/j.brainresbull.200 9.02 .001

79. Miao X, Huang H, Hu X, Li D, Yu Y, Ao Y. The characteristics of EEG power spectra changes after ACL rupture. PLoS ONE. 2017;12(2):e0170455. doi:1 $\underline{0.1371 / \text { journal.pone. } 0170455}$

80. Nagelli CV, Hewett TE. Should return to sport be delayed until two years after anterior cruciate ligament reconstruction? Biological and functional considerations. Sports Med. 2017;47(2):221-232. doi:1 $\underline{0.1007 / \mathrm{s} 40279-016-0584-\mathrm{Z}}$

81. Read PJ, Michael Auliffe S, Wilson MG, GrahamSmith P. Lower limb kinetic asymmetries in professional soccer players with and without anterior cruciate ligament reconstruction: Nine months is not enough time to restore "functional" symmetry or return to performance. Am J Sports Med. 2020;48(6):1365-1373. doi:10.1177/036354652091221 8 
82. Beischer S, Gustavsson L, Senorski EH, et al. Young athletes who return to sport before 9 months after anterior cruciate ligament reconstruction have a rate of new injury 7 times that of those who delay return. J Orthop Sports Phys Ther. 2020;50(2):83-90. $\underline{\mathrm{d}}$ oi:10.2519/jospt.2020.9071

83. Warren WH, Kay BA, Zosh WD, Duchon AP, Sahuc S. Optic flow is used to control human walking. Nat Neurosci. 2001;4(2):213-216. doi:10.1038/84054

84. Smith WM, Bowen KF. The effects of delayed and displaced visual feedback on motor control. $J \mathrm{Mot}$ Behav. 1980;12(2):91-101. doi:10.1080/00222895.198 0.10735209

85. Benjaminse A, Otten E. ACL injury prevention, more effective with a different way of motor learning? Knee Surg Sports Traumatol Arthrosc Off J ESSKA. 2011;19(4):622-627. doi:10.1007/s00167-010-1313-z

86. Ageberg E, Fridén T. Normalized motor function but impaired sensory function after unilateral nonreconstructed ACL injury: patients compared with uninjured controls. Knee Surg Sports Traumatol Arthrosc Off J ESSKA. 2008;16(5):449-456. doi:10.100 7/s00167-008-0499-9

87. Hall KG, Magill RA. Variability of practice and contextual interference in motor skill learning. $J \mathrm{Mot}$ Behav. 1995;27(4):299-309. doi:10.1080/00222895.19 $\underline{95.9941719}$

88. Kim K-M, Kim J-S, Grooms DR. Stroboscopic vision to induce sensory reweighting during postural control. J Sport Rehabil. 2017;26(5). doi:10.1123/isr.20 17-0035

89. Wilkins L, Appelbaum L. An early review of stroboscopic visual training: insights, challenges and accomplishments to guide future studies. Int Rev Sport Exerc Psychol. March 2019:1-16. doi:10.1080/17 50984X.2019.1582081

90. Appelbaum LG, Schroeder JE, Cain MS, Mitroff SR. Improved visual cognition through stroboscopic training. Front Psychol. 2011;2:276. doi:10.3389/fpsy g.2011.00276

91. Appelbaum LG, Cain MS, Schroeder JE, Darling EF, Mitroff SR. Stroboscopic visual training improves information encoding in short-term memory. Atten Percept Psychophys. 2012;74(8):1681-1691. doi:10.375 8/s13414-012-0344-6

92. Smith TQ, Mitroff SR. Stroboscopic training enhances anticipatory timing. Int J Exerc Sci. 2012;5(4):344-353.
93. Dale RB, Gollapalli RP, Price T, et al. The effect of visual perturbation upon femoral acceleration during the single and bilateral squat. Off J Assoc Chart Physiother Sports Med. 2017;27:24-28. doi:10.1016/j.p tsp.2017.06.003

94. Mitroff S, Friesen P, Bennett D, Yoo H, W. Reichow A. Enhancing ice hockey skills through stroboscopic visual training: a pilot study. Athl Train Sports Health Care. 2013;5:261-264. doi:10.3928/19425864-2013103 $\underline{0-02}$

95. Wilkins L, Gray R. Effects of Stroboscopic visual training on visual attention, motion perception, and catching performance. Percept Mot Skills. 2015;121(1):57-79. doi:10.2466/22.25.PMS.121c11x0

96. Hülsdünker T, Rentz C, Ruhnow D, Käsbauer H, Strüder HK, Mierau A. The effect of 4-Week stroboscopic training on visual function and sportspecific visuomotor performance in top-level badminton players. Int J Sports Physiol Perform. 2019;14(3):343-350. doi:10.1123/ijspp.2018-0302

97. Bennett SJ, Hayes SJ, Uji M. Stroboscopic vision when interacting with multiple moving objects: Perturbation is not the same as elimination. Front Psychol. 2018;9:1290. doi:10.3389/fpsyg.2018.01290

98. Di Stasi S, Myer GD, Hewett TE. Neuromuscular training to target deficits associated with second anterior cruciate ligament injury. J Orthop Sports Phys Ther. 2013;43(11):777-792, A1-11. doi:10.2519/josp t.2013.4693

99. McLean SG, Lipfert SW, van den Bogert AJ. Effect of gender and defensive opponent on the biomechanics of sidestep cutting. Med Sci Sports Exerc. 2004;36(6):1008-1016.

100. Houck JR, Wilding GE, Gupta R, De Haven KE, Maloney M. Analysis of EMG patterns of control subjects and subjects with ACL deficiency during an unanticipated walking cut task. Gait Posture. 2007;25(4):628-638. doi:10.1016/i.gaitpost.2006.07.00 $\underline{1}$

101. Myer GD, Stroube BW, DiCesare CA, et al. Augmented feedback supports skill transfer and reduces high-risk injury landing mechanics: a doubleblind, randomized controlled laboratory study. Am J Sports Med. 2013;41(3):669-677. doi:10.1177/0363546 512472977

102. Gokeler A, Benjaminse A, Hewett TE, et al. Feedback techniques to target functional deficits following anterior cruciate ligament reconstruction: Implications for motor control and reduction of second injury risk. Sports Med. 2013;43(11):1065-1074. doi:10.1007/s40279-013-009 $\underline{5-0}$ 
103. Pringle R. Motor learning and performance: A problem-based learning approach. J Manipulative Physiol Ther. 2000;23:300-301. doi:10.1016/S0161-47 54(00)90186-6

104. Pearce AJ, Thickbroom GW, Byrnes ML, Mastaglia FL. Functional reorganisation of the corticomotor projection to the hand in skilled racquet players. Exp Brain Res. 2000;130(2):238-243. doi:10.1 $\underline{007 / s 002219900236}$

105. Pearce AJ, Hendy A, Bowen WA, Kidgell DJ. Corticospinal adaptations and strength maintenance in the immobilized arm following 3 weeks unilateral strength training. Scand J Med Sci Sports. 2013;23(6):740-748. doi:10.1111/j.1600-0838.2012.01 453.X

106. Lohse KR, Sherwood DE, Healy AF. How changing the focus of attention affects performance, kinematics, and electromyography in dart throwing. Hum Mov Sci. 2010;29(4):542-555. doi:10.1016/j.hum ov.2010.05.001

107. Gokeler A, Seil R, Kerkhoffs G, Verhagen E. A novel approach to enhance ACL injury prevention programs. J Exp Orthop. 2018;5(1):22. doi:10.1186/s40 $\underline{634-018-0137-5}$

108. Matthis JS, Yates JL, Hayhoe MM. Gaze and the control of foot placement when walking in natural terrain. Curr Biol. 2018;28(8):1224-1233.e5. doi:10.10 16/j.cub.2018.03.008

109. McNevin NH, Shea CH, Wulf G. Increasing the distance of an external focus of attention enhances learning. Psychol Res. 2003;67(1):22-29. doi:10.1007/s 00426-002-0093-6

110. Seidler RD, Noll DC. Neuroanatomical correlates of motor acquisition and motor transfer. $J$ Neurophysiol. 2008;99(4):1836-1845. doi:10.1152/jn.0 $\underline{1187.2007}$

111. Powers CM, Fisher B. Mechanisms underlying ACL injury-prevention training: The brain-behavior relationship. J Athl Train. 2010;45(5):513-515. doi:1 $\underline{0.4085 / 1062-6050-45.5 .513}$

112. Wulf G. Attentional focus and motor learning: a review of 15 years. Int Rev Sport Exerc Psychol. 2013;6(1):77-104. doi:10.1080/1750984X.2012.723728

113. Benjaminse A, Welling W, Otten B, Gokeler A. Novel methods of instruction in ACL injury prevention programs, a systematic review. Phys Ther Sport. 2015;16(2):176-186. doi:10.1016/i.ptsp.2014.0 $\underline{6.003}$
114. Wulf G, Dufek JS, Lozano L, Pettigrew C. Increased jump height and reduced EMG activity with an external focus. Hum Mov Sci. 2010;29(3):440-448. doi:10.1016/j.humov.2009.11.008

115. Gokeler A, Benjaminse A, Welling W, Alferink M, Eppinga P, Otten B. The effects of attentional focus on jump performance and knee joint kinematics in patients after ACL reconstruction. Phys Ther Sport . 2015;16(2):114-120. doi:10.1016/i.ptsp.2014.06.002

116. Lohse KR, Sherwood DE. Defining the focus of attention: Effects of attention on perceived exertion and fatigue. Front Psychol. 2011;2. doi:10.3389/fpsy g.2011.00332

117. Kuhn Y-A, Keller M, Ruffieux J, Taube W. Adopting an external focus of attention alters intracortical inhibition within the primary motor cortex. Acta Physiol (Oxf). 2017;220(2):289-299. doi:1 0.1111/apha.12807

118. Kuhn Y-A, Keller M, Lauber B, Taube W. Surround inhibition can instantly be modulated by changing the attentional focus. Sci Rep. 2018;8. doi:1 $\underline{0.1038 / \mathrm{s} 41598-017-19077-0}$

119. Gluck MA, Mercardo E, Myers CE. Learning and Memory: From Brain to Behavior. New York City, New York: Worth Publishers; 2008.

120. Honda M, Deiber MP, Ibáñez V, Pascual-Leone A, Zhuang P, Hallett M. Dynamic cortical involvement in implicit and explicit motor sequence learning. A PET study. Brain J Neurol. 1998;121 ( Pt 11):2159-2173. do i:10.1093/brain/121.11.2159

121. Hirano M, Kubota S, Koizume Y, Tanaka S, Funase K. Different effects of implicit and explicit motor sequence learning on latency of motor evoked potential evoked by transcranial magnetic stimulation on the primary motor cortex. Front Hum Neurosci. 2017;10. doi:10.3389/fnhum.2016.00671

122. Masters RSW, Poolton JM, Maxwell JP, Raab M. Implicit motor learning and complex decision making in time-constrained environments. J Mot Behav. 2008;40(1):71-79. doi:10.3200/JMBR.40.1.71-80

123. Meinerz CM, Malloy P, Geiser CF, Kipp K. Anticipatory effects on lower extremity neuromechanics during a cutting task. J Athl Train. 2015;50(9):905-913. doi:10.4085/1062-6050-50.8.02

124. Niemeyer P, Niederer D, Giesche F, et al. Unanticipated jump-landing after anterior cruciate ligament reconstruction: Does unanticipated jumplanding testing deliver additional return to sport information to traditional jump performance tests? Clin Biomech Bristol Avon. 2019;70:72-79. doi:10.101 6/i.clinbiomech.2019.08.003 
125. Niederer D, Giesche F, Janko M, et al.

Unanticipated jump-landing quality in patients with anterior cruciate ligament reconstruction: How long after the surgery and return to sport does the reinjury risk factor persist? Clin Biomech. 2020;72:195-201. doi:10.1016/j.clinbiomech.2019.1 2.021

126. Zhang S, Fu W, Liu Y. Changes in lower-limb biomechanics, soft tissue vibrations, and muscle activation during unanticipated bipedal landings. $J$ Hum Kinet. 2019;67:25-35. doi:10.2478/hukin-2019-0 $\underline{003}$
127. Hart SG, Staveland LE. Development of NASATLX (Task Load Index): Results of empirical and theoretical research. In: Human Mental Workload. Advances in psychology, 52. Oxford, England: NorthHolland; 1988:139-183. doi:10.1016/ S0166-4115(08)62386-9

128. Borg G. Perceived exertion as an indicator of somatic stress. Scand J Rehabil Med. 1970;2(2):92-98.

129. Borg GA. Psychophysical bases of perceived exertion. Med Sci Sports Exerc. 1982;14(5):377-381. 